\title{
Drivers' Parking Location Choice under Uncertain Parking Availability and Search Times: A Stated Preference Experiment
}

\author{
Emmanouil Chaniotakis ${ }^{\mathrm{a}, \mathrm{b}}$, Adam J. Pel ${ }^{\mathrm{c}}$ \\ ${ }^{a}$ Centre for Research and Technology Hellas - Hellenic Institute of Transport, $6^{\text {th }} \mathrm{km}$ Charilaou-Thermi Rd., 57001 Thermi, \\ Thessaloniki, Greece \\ ${ }^{b}$ National Technical University of Athens, School of Rural and Surveying Engineering, Zografou 15780, Greece \\ ${ }^{c}$ Department of Transport and Planning, Faculty of Civil Engineering and Geosciences, Delft University of Technology, \\ Stevinweg 1, 2628 CN Delft, The Netherlands
}

\begin{abstract}
To assess parking pricing policies and parking information and reservation systems, it is essential to understand how drivers choose their parking location. A key aspect is how drivers' behave towards uncertainties towards associated search times and finding a vacant parking spot. This study presents the results from a stated preference experiment on the choice behaviour of drivers, in light of these uncertainties. The attribute set was selected based on a literature review, and appended with the probabilities of finding a vacant parking spot upon arrival and after 8 minutes (and initially also after 4 minutes, but later dropped to reduce the survey complexity). Efficient Designs were used to create the survey design, where two rounds of pilot studies were conducted to estimate prior coefficients. Data was successfully collected from 397 respondents. Various random utility maximisation (RUM) choice models were estimated, including multinomial logit, nested logit, and mixed logit, as well as models accounting for panel effects. These model analyses show how drivers appear to accept spending time on searching for a vacant parking spot, where parking availability after 8 minutes ranks second most important factor in determining drivers' parking decisions, while parking availability upon arrival ranks fourth. Furthermore, the inclusion of heterogeneity in preferences and interdriver differences is found to increase the predictive power of the parking location choice model. The study concludes with an outlook of how these insights into drivers' parking behaviour can be incorporated into traffic assignment models and used to support parking systems.
\end{abstract}

Keywords: parking, parking uncertainty, choice behaviour, choice factors, stated preference

\section{Introduction}

One of the negative effects that can be associated to parking in urban areas is the presence of cruising traffic. That is, drivers may need to drive around while searching for a vacant parking spot. This leads to additional traffic on the urban network. Studies by Axhausen et al. (1994), Arnott \& Inci (2006), and 5 Shoup (2006) found that at certain moments during the day up to 50 percent of the traffic is related to cruising for parking. This evidently is a contributor to problems regarding congestion levels, travel times, emissions, and traffic safety (McCoy et al., 1990; Shoup, 2006). These problems can be addressed by parking policies (e.g., pricing policies and/or parking permits) as well as through the use of Parking Guidance and Information (PGI) and Parking Reservation systems. Many studies in the literature have particularly focused 10 on designing efficient pricing policies (Gillen, 1978; Anderson \& de Palma, 2004; Calthrop \& Proost, 2006; Mei et al., 2010; Ottosson et al., 2013; Millard-Ball et al., 2014) and permit schemes (Liu et al., 2014a,b; Barata et al., 2011), also in light of drivers' willingness to pay for parking (Hess \& Polak, 2004; Ibeas et al.,

\footnotetext{
* Corresponding author

Email address: chaniotakis@certh.gr (Emmanouil Chaniotakis)
} 
2014). At the same time, others argue that what can be achieved via parking pricing and permit policies is limited due to social and political constraints (Verhoef et al., 1995; Lam et al., 2006). In this regard, 15 Intelligent Transport Systems (ITS) aimed at informing and guiding drivers towards vacant parking spots and at allowing drivers to reserve parking spots have good prospects (Thompson \& Bonsall, 1997).

In accordance to the solutions proposed, researchers have developed traffic assignment and simulation models to be used for their evaluation. To name but a few, Thompson \& Richardson (1998) presented a simulation parking search model in which individuals search for parking space and accept or reject the 20 vacant parking spots based on a disutility function as well as a function to represent the likelihood to select a particular turning movement. Lam et al. (2006) proposed a model for user equilibrium flows that accounts for the departure time, parking location and parking duration. A Bureau of Public Roads based (BPR) function is used as a cost function and the model includes multiple user classes and car parks. In the same direction, Gallo et al. (2011) derived a simulation-based parking assignment model with a 25 hierarchical structure simulating parking location choices on a trip, a cruising and a walking layer, whereas Guo et al. (2013) presents an assignment model for strategic parking route choice decisions under uncertainty. Leurent \& Boujnah (2014) give a very detailed analysis of the network flows under the assumption of drivers choosing their parking location and rerouting based on expected conditions in combination with the stochastic realization of actual parking occupancies. Others have employed a different modelling approach by specifically considering the searching behaviour of drivers. For example, Young \& Taylor (1991) describes PARKSIM as a model that describes the parking search within a car park, and Benenson et al. (2008); Levy et al. (2015) developed PARKAGENT; an agent-based model to explicitly simulate the spatial search process and navigation behaviour of drivers.

Evidently, the (model-based) design and evaluation of such parking-oriented ITS and the derivation of 35 policies on parking require a valid understanding of drivers' choice behaviour among alternative parking locations, as well as their willingness-to-pay, usage, and acceptance towards these systems. In this paper, we focus on the former, here termed as parking location choice behaviour, which can improve the assignment and simulation models developed for evaluation and has also clear implication for parking-related policies.

Earlier studies on parking location choice have aimed at identifying the determining factors for drivers' 40 parking decisions (Gillen, 1978; Van Der Goot, 1982; Polak et al., 1991; Brandley et al., 1993; Hunt \& Teply, 1993; Lambe, 1996). Other studies have investigated parking location choice in combination with related travel decisions, such as trip purpose (Van der Waerden \& Oppwal, 1995; Shiftan \& Burd-Eden, 2001) and mode of transport (Hensher \& King, 2001; Hess, 2001; Coppola, 2004), as well as route choice of cruising traffic (Guo et al., 2013; Leurent \& Boujnah, 2014). Typically, the influence of these factors is studied through the estimation of discrete choice models, where these models are based on stated preference experiments. Attributes that are recurrently reported are parking costs, walking distance to destination, access time, expected search time or waiting time at parking location, and to a lesser degree driver's age, type of parking facility, and parking duration. With respect to the design and evaluation of parking information, guidance, and reservation systems, what is especially of interest is how drivers' parking location choice

50 is affected by uncertainties in finding a vacant parking spot. In this regard, only the study by Van der Waerden (2012) explicitly accounts for the chance (probability) of finding a vacant parking spot. There, parking availability probabilities are found to be significant for the choice set generation, where a higher probability to find a vacant parking spot relates to a higher probability to choose that parking location. In line, Kaplan \& Bekhor (2011) presented a theoretical framework with a hierarchical structure where on-route

55 the preferred parking type determines the preferred parking location, which in turn determines the preferred route towards this destination.

The experiments reported in this paper were part of a larger study to investigate the viability of parkingoriented ITS. Here the main target group of a (future) parking guidance and reservation system was chosen to be drivers who make a trip for shopping purposes and park for a duration of 2-3 hours. Hence, this is 60 also the context for the remainder of this paper.

This way, this paper first of all adds to the existing body of the literature (including the studies by Kaplan \& Bekhor (2011) and Van der Waerden (2012)) using stated preference experiments to understand parking location choice behaviour in case of uncertain search times and parking occupancy levels. Second of all, we analyse drivers' parking location choice and show the importance of uncertain parking availability 
as a determining choice factor, as well as the heterogeneity in preferences and inter-driver differences in this respect. Third of all, we estimate choice models that can be readily incorporated in both disaggregated microscopic simulation models as well as aggregated macroscopic traffic assignment models. Finally, we discuss the quantified behavioural findings and conclusions within this paper with respect to their implications on parking-related policies and transportation modelling.

The structure of this paper is as follows: We first introduce the stated preference experiments on drivers' parking location choice in Section 2. The estimated parking location choice models are then presented in Section 3. The main behavioural findings from these models are discussed in Section 4. In Section 5, we conclude with an outlook towards including drivers' parking location choice behaviour in traffic assignment models to support the evaluation of parking systems.

Note that throughout the paper, uncertainty concerning parking availability and search times refers to the situation in which the outcome is unknown, but the set of possible outcomes and their probabilities are known. This terminology is consistent with the larger body of parking-related literature. However, note that in many other lines of research this situation would typically be referred to as risk (while uncertainty would be used to indicate that the set of possible outcomes and their probabilities are unknown).

\section{Stated Preference Experiment}

In order to understand drivers' parking location choice a series of stated preference experiments were conducted in the form of internet-based questionnaires. In this section, we first describe the attribute set and levels (in Section 2.2) where the set includes attributes accounting for the probability of acquiring a vacant parking spot upon arrival, and after 8 minutes. The survey method is briefly illustrated (in Section 2.1), after which the experiment design is derived through two pilot studies (explained in Section 2.3). The collected data set of 397 successful respondents is discussed in terms of descriptive statistics (in Section 2.4). This stated preference data is used in Section 3 to estimate various parking location choice models.

\subsection{Questionnaire and Survey design}

The survey conducted was internet-based using the LimeSurvey open-source platform and run on a server at Delft University of Technology. The survey consisted of three parts.

The first part pertained to questions on the personal characteristics of the respondent: gender, age, education, income, and home postcode. Furthermore, two questions were asked regarding drivers licence possession and frequency of private car trips to the city centre ("How often do you drive to the city centre for shopping?"). Only in case participants were with drivers licence and drove to the city centre at least 95 once per month, the survey continued.

The second part pertained to questions on parking behaviour in an unfamiliar area. These questions related to aspects of acceptable search times and on-route decisions to reroute towards another parking location. The particular questions and formulation were refined during the pilot studies. The first question of the second part was a closed question on their strategy users undertake when driving to a city centre they are unfamiliar ("What do you usually do when you want to visit a city you are not familiar with?"). The given answers were either search pre-trip for available parking locations, search upon arrival to destination or search when arriving close to the destination. The second question referred to preference upon on-street or off-street parking ("Which of the following options seems more attractive to you for 2-3 hours of parking?"), while the third question referred to the reaction in case of not finding a vacant parking spot after 5 minutes for their case of on-street or off-street parking (i.e. "What do you do if you do not find a vacant parking spot at your selected parking lot after waiting for 5 minutes?"). Finally, the forth question referred to the maximum search duration (or waiting time in case of off-street parking) that respondents were willing to spend "What is the maximum duration of waiting before going to another parking facility?").

The third part showed a series of choice situations where the respondent was every time asked to select her/his preferred parking location from two alternatives. A screenshot of such a choice situation is shown in Figure 1. In total 12 choice situations were shown, based on the selected attributes (Section 2.2) where the attribute levels were based on an efficient experiment design explained in Section 2.3.

Respondents had the option to complete the survey in either English or Dutch. 


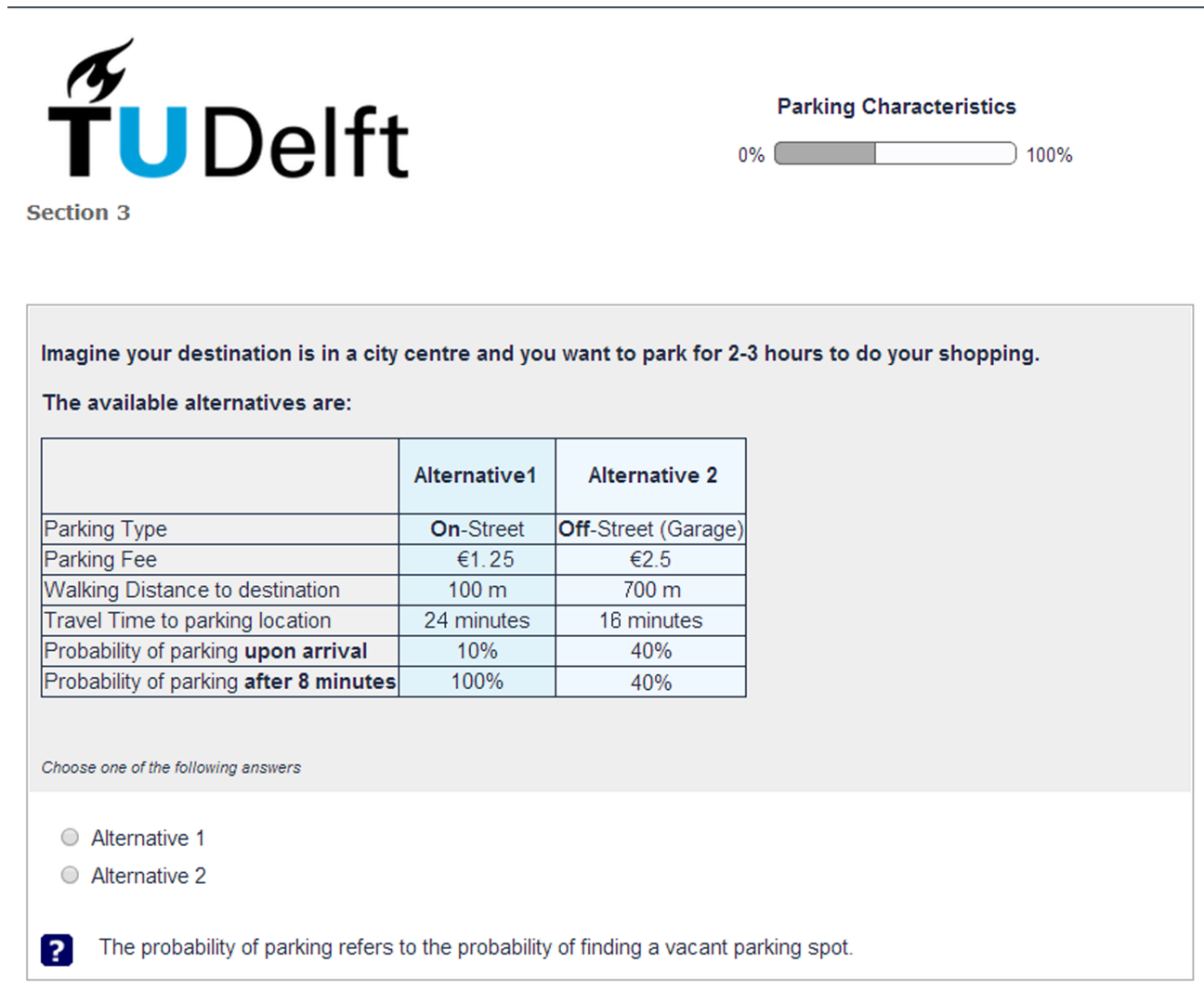

\begin{tabular}{|c|c|c|}
\hline Resume later & $\ll$ Previous & Next $\gg$ \\
\hline
\end{tabular}

Figure 1: Screenshot of choice situation in survey

\subsection{Attribute selection}

Table 1 gives an overview of the attributes that in earlier studies have been found to have a statistically significant influence on drivers' parking location choice. As observed, parking location choice is a rather complex decision process with many factors potentially playing a role. At the same time, the inclusion of a large number of attributes creates large dimensions in a stated preference context that can result in biased model estimation (Caussade et al., 2005; Hensher, 2006).

For this reason, in our stated preference experiments we chose to limit the number of choice situations, attributes, and attribute levels, such that an efficient experiment design (Rose \& Bliemer, 2008) and reasonable number of respondents would still yield satisfactory results. While evidently the primary attributes as well as the attributes pertaining to probabilities in parking availability are included.

This attribute set consists of the attributes that are reported among earlier studies, and appended with the probability of finding a parking spot upon arrival, and after 8 minutes. The uncertainty in finding a parking spot is included in this way, as it is believed to be intuitively understandable for respondents. Furthermore, the influence of the probability of a parking spot upon arrival is interesting as it directly relates to the benefit of parking information and guidance systems (where this probability would be 1). The probability after 8 minutes is included to test how search times are appreciated, while 8 minutes is suggested to be within the range of an acceptable search time before rerouting to a different parking area (found as average cruising time for on-street parking by Shoup (2006), and also suggested from our pilot studies, see Section 2.3.1).

For reasons of model estimation, we limit all attributes to 2 attribute levels. The initial values for the 
Table 1: Parking choice model attributes reported in literature

\begin{tabular}{|c|c|c|c|c|c|c|c|c|c|c|c|c|c|}
\hline Study & $\begin{array}{l}\text { Park } \\
\text { Cost }\end{array}$ & $\begin{array}{l}\text { Walk } \\
\text { Dist. }\end{array}$ & $\begin{array}{l}\text { Access } \\
\text { Time }\end{array}$ & $\begin{array}{l}\text { Search } \\
\text { Time }\end{array}$ & $\begin{array}{l}\text { Dura- } \\
\text { tion }\end{array}$ & Type $^{\mathrm{a}}$ & Age & $\begin{array}{l}\text { Illegal } \\
\text { fine }\end{array}$ & $\begin{array}{l}\text { Pur- } \\
\text { pose }\end{array}$ & Inc. & $\mathrm{PGI}^{\mathrm{b}}$ & $\begin{array}{l}\text { Occu- } \\
\text { pancy } \\
\text { c }\end{array}$ & Prob. $^{\mathrm{d}}$ \\
\hline 1 & $\checkmark$ & $\checkmark$ & $\checkmark$ & $\checkmark$ & & & $\checkmark$ & & & $\checkmark$ & & & \\
\hline 2 & $\checkmark$ & $\checkmark$ & $\checkmark$ & $\checkmark$ & & $\checkmark$ & & & & & & & \\
\hline 3 & $\checkmark$ & & & & $\checkmark$ & & & & & & & & \\
\hline 4 & $\checkmark$ & $\checkmark$ & $\checkmark$ & $\checkmark$ & & & & $\checkmark$ & & & & & \\
\hline 5 & $\checkmark$ & $\checkmark$ & $\checkmark$ & $\checkmark$ & & $\checkmark$ & & & & & & & \\
\hline 6 & $\checkmark$ & $\checkmark$ & $\checkmark$ & & & & & & & & & & \\
\hline 7 & $\checkmark$ & $\checkmark$ & $\checkmark$ & $\checkmark$ & $\checkmark$ & & & $\checkmark$ & & & & & \\
\hline 8 & $\checkmark$ & $\checkmark$ & $\checkmark$ & $\checkmark$ & & & & & $\checkmark$ & & & & \\
\hline 9 & $\checkmark$ & $\checkmark$ & $\checkmark$ & & & & & & & & $\checkmark$ & & \\
\hline 10 & $\checkmark$ & $\checkmark$ & & & & $\checkmark$ & $\checkmark$ & & & & & $\checkmark$ & \\
\hline 11 & $\checkmark$ & $\checkmark$ & $\checkmark$ & $\checkmark$ & $\checkmark$ & $\checkmark$ & $\checkmark$ & & $\checkmark$ & $\checkmark$ & $\checkmark$ & $\checkmark$ & $\checkmark$ \\
\hline
\end{tabular}

where:

$\begin{array}{llll}\text { 1. } & \text { Gillen (1978) } & 7 . & \text { Thompson \& Richardson (1998) } \\ \text { 2. } & \text { Hunt (1988) } & 8 . & \text { Dell'Orco et al. (2003) } \\ \text { 3. } & \text { Kanafani (1983) } & 9 . & \text { Bonsall \& Palmer (2004) } \\ \text { 4. } & \text { Axhausen \& Polak (1991) } & \text { 10. } & \text { Ruisong et al. (2009) } \\ 5 . & \text { Hunt \& Teply (1993) } & 11 . & \text { Van der Waerden (2012) } \\ 6 . & \text { Lambe (1996) } & & \end{array}$

pilot studies were chosen as lower and upper bound on a range that is deemed realistic. The final attribute levels are determined after the two pilot studies.

This way the final attribute level values were set as follows. The level values for parking price were set at $€ 1.25$ and $€ 2.50$ per hour. Parking near shopping areas in the Netherlands is typically paid, where the average hourly fee in a Dutch city centre is $€ 1.55$ for on-street parking and $€ 1.52$ for off-street parking (Van Ommeren et al., 2012). Hourly parking fees in larger cities such as Rotterdam and Amsterdam tend to be higher (respectively $€ 3.00$ and $€ 5.00$ ). In general, parking prices do not considerably differ among parking areas within the same vicinity of a shopping area, and free parking is not available within reasonable walking distance. The level values for distance to destination were set at 100 meters and 700 meters. The upper level is based on what is found as maximum reasonable walking distance in studies on catchment areas of urban transit stops (Kittelson \& Associates, 2003, p.3-93). The level values for travel time to parking area were set at 16 minutes and 24 minutes. These values are deemed realistic within the context of a car trip for shopping in a Dutch city centre. For the parking type, we distinguish on-street and off-street parking, where the first relates to curb-side (on-street) parking and the latter relates to a (often monitored) parking facility (off-street). This attribute was included as the way in which parking information and guidance systems would operate may differ between these parking types. Finally, the probability values for finding a vacant spot were set at 10,40, and 70 percent, and at 40,70, and 100 percent after 8 minutes. Infeasible combinations of level values where the probability would decrease after time were evidently excluded.

\subsection{Experiment design}

The design of the experiment followed a three phase procedure to fully benefit from using a wellformulated efficient design (Rose \& Bliemer, 2009). The usefulness of such a multilevel approach is twofold. Firstly, this approach allows the adaptation of the question's formulation and focus, in order to make them realistic and understandable - especially with respect to the stated preference part of the survey. Secondly, this approach allows the increase of the information to be obtained from the (final) experimental design due to a better model estimation-, against the conventional approach of using orthogonal designs (Louviere et al., 2000; Antony, 2003) and eliminating dominant alternatives, as it has been found that even with little 
information on the estimates (priors) the experiment design would yield more information (Rose et al., 2008; Bliemer et al., 2009). The measure of information was evaluated on the $\min _{x \in X_{i d}} \operatorname{det}\left(P_{\theta}\right)$ (D-optimality) where $P_{\theta}$ denotes the covariance matrix.

A first round pilot study was designed based on prior coefficient estimates reported in literature. Then, a second round pilot study was designed based on the model coefficient estimates from the first pilot study. Finally, the estimated model from the second pilot was used to generate an efficient design for the final survey. These pilot studies are discussed first, before presenting the final design.

All reported experiment designs were generated using the Ngene software (ChoiceMetrics, 2012) and all reported choice models were estimated using the Biogeme software (Bierlaire, 2006) and mLogit library for R software (Croissant et al., 2012).

\subsubsection{Pilot studies}

Two pilot studies were undertaken in order to derive prior coefficient estimates for the efficient design of the final experiment. Both pilot studies were distributed among students and employees at Delft University of Technology and at Dutch Organisation for Applied Research (TNO). Both pilot studies were accompanied with an evaluation that was used to assess the complexity of the (internet-based) survey and for content improvements.

The first pilot study was created based on a combination of the available priors $(0 L P r)$ reported in the studies by Van der Waerden (2012) and Axhausen \& Polak (1991). In this design there were some dominant alternatives in some scenarios and the information that could be acquired was not maximum (i.e., the design was sub-optimal) mainly due to the fact that priors were harvested from two studies. However, this design did accommodate more information than an orthogonal design (which yielded a higher number of dominant scenarios) and it was chosen to be implemented in the first round of the pilot study with a small sample.

After acquiring the answers from 11 respondents, a random utility maximisation (RUM) multinomial logit (MNL) model was estimated. These RUM-MNL model coefficients are evidently not an accurate representation of drivers' parking location choice due to the setup of the survey design and small (unstratified) sample size. However, these coefficients served well as priors to the second pilot $(1 L P r)$. Furthermore, a number of minor changes were made to the survey design, based on the evaluation feedback. The upper level of the walking distance to destination was increased to 700 meters, because a number of respondents indicated an indifference between 100 meters and 500 meters (initial value). The travel time to parking area was increased (from initially 6 and 12 minutes to fianlly 16 and 24 minutes), as many respondents mentioned that in case of initially chosen lower travel times, the bicycle would be the preferred mode of transport.

The second pilot study was created based on the estimates from the first pilot study. The experiment design was generated without dominant scenarios and had a D-error of 0.10 . The survey was completed by 35 respondents, and again a RUM-MNL model was estimated. All coefficients had the correct sign, where price, walking distance, and travel time are negative and parking type (where 1 indicates off-street parking) all vacancy probabilities are positive. Alternative specific constants were checked for, but found not statistically significant (i.e. there was no significant unexplained bias towards a specific choice situation within the survey, which was expected as the alternatives were unlabelled). Heterogeneity in the preferences was tested by estimating a RUM mixed-MNL model, but the variances in the coefficients were found not statistically significant (i.e. there were no significant differences in the parking location choice preferences of the respondents). The RUM-MNL estimates were therefore used in the final design.

The survey evaluation feedback showed that the survey was experienced as time-consuming and rather difficult to complete due to the high number of attributes. Many respondents indicated that they therefor eliminated some attributes and made decisions based on those they considered as most important. This corresponds with the findings by Hensher (2006) and Caussade et al. (2005) about stated preference survey complexity where they caution for biased coefficient estimates. This issue was addressed by making the following adjustments

- The attribute on the probability of finding a vacant parking spot after 4 minutes was dropped.

- The lower level of the parking price was changed from $€ 1.50$ to $€ 1.25$ in order to increase the attribute range. 
- The size of the design was set at 24 choice situations and divided into two blocks such that each respondent was shown 12 choice situations.

\subsubsection{Final design}

The attributes and levels included in the final design are summarised in Table 2. The final design for the choice situations was based on the priors derived by the second round of the pilot study $(2 L P r)$. Again, combinations of levels and model structures were tested using as a benchmark the D-error. As the priors of the model were fixed, the level values within the range of the level values used for the model calculation resulted in different models. It was found that for the probability attributes, a design of 3 levels would have better results in acquiring the most information (given the number of attributes and the number of choice situations). The D-error of the final design is 0.01. The Fisher information matrix is shown in Table 3. The final design is shown in Table 4.

Table 2: Survey attributes and values in final design

\begin{tabular}{llccc}
\hline Attributes & Levels & & Level Values \\
\cline { 1 - 1 } Cost $(C)$ & & & $€ 1.25 / € 2.5$ \\
Distance to destination (walking) $(W)$ & & & 100 meters / 700 meters \\
Travel time $(T)$ & & & 16 min / 24 min \\
Parking type $(P)$ & & 2 & & On-Street / Off-Street \\
Probability upon arrival $\left(\operatorname{Pr}^{0}\right)$ & & 3 & & $10 \%, 40 \%, 70 \%$ \\
Probability after 8 minutes $\left(P r^{8}\right)$ & & 3 & & $40 \%, 70 \%, 100 \%$ \\
\hline
\end{tabular}

Table 3: Fisher Information Matrix of final design

\begin{tabular}{c|cccccc}
\hline Prior & $\beta_{C}$ & $\beta_{W}$ & $\beta_{T}$ & $\beta_{P}$ & $\beta_{P r^{0}}$ & $\beta_{P r^{8}}$ \\
\hline$\beta_{C}$ & 8.082 & -276.819 & -8.516 & 0.401 & 0.881 & 0.732 \\
$\beta_{W}$ & -276.819 & 1862152 & -2401.330 & 667.310 & 470.678 & 504.556 \\
$\beta_{T}$ & -8.516 & -2401.330 & 331.049 & 2.840 & 4.392 & 3.123 \\
$\beta_{P}$ & 0.401 & 667.311 & 2.840 & 5.173 & -0.368 & -0.148 \\
$\beta_{P r^{0}}$ & 0.881 & 470.678 & 4.396 & -0.368 & 1.232 & -0.015 \\
$\beta_{P r^{8}}$ & 0.733 & 504.556 & 3.123 & -0.148 & -0.015 & 1.554 \\
\hline
\end{tabular}

\subsection{Data set}

Survey respondents were recruited via the Dutch company Respondenten Database who maintain a panel of people who are paid to participate in this type of surveys. From 460 total respondents, 397 respondents were found to have completed the survey successfully. This sample size is considered representative of the car-driving population in the Netherlands (where the minimum sample size equals 384 respondents with a degree of accuracy of 0.05 according to the method by Krejcie \& Morgan (1970)). Furthermore, the distribution of gender, age, and highest level of education in the sample corresponds with the statistics of the Dutch population (based on the Dutch Bureau of Statistics data for 2009 (CBS, 2009)). Table 5 summarises the socio-demographic and personal characteristics of the respondents, while Table 6 contains respondents across income levels was not checked.

In the second part of the survey, respondents were asked about their parking search strategy, their preferred parking type, their behaviour after 5 minutes of searching (or waiting), and their maximum searching (or waiting) time in case of being unfamiliar with the parking location.

Regarding parking search strategy, 145 respondents $(36.6 \%)$ indicated that they decide upon their parking area pre-trip, while 199 respondents $(50.1 \%)$ stated they start searching for parking once they 
Table 4: Final experiment design

\begin{tabular}{|c|c|c|c|c|c|c|c|c|c|c|c|c|c|}
\hline \multirow{2}{*}{ Choices } & \multicolumn{6}{|c|}{ Alternative 1} & \multicolumn{6}{|c|}{ Alternative 2} & \multirow{2}{*}{ Block } \\
\hline & $C_{1}$ & $W_{1}$ & $T_{1}$ & $P_{1}$ & $P r_{1}^{0}$ & $\operatorname{Pr}_{1}^{8}$ & $C_{2}$ & $W_{2}$ & $T_{2}$ & $P_{2}$ & $\operatorname{Pr}_{2}^{0}$ & $\operatorname{Pr}_{2}^{8}$ & \\
\hline 1 & 1.25 & 100 & 24 & 1 & 0.1 & 0.4 & 2.5 & 700 & 16 & 0 & 0.7 & 1 & 1 \\
\hline 2 & 1.25 & 100 & 24 & 0 & 0.1 & 1 & 2.5 & 700 & 16 & 1 & 0.4 & 0.4 & 1 \\
\hline 3 & 2.5 & 100 & 16 & 1 & 0.1 & 1 & 1.25 & 700 & 24 & 0 & 0.7 & 0.7 & 2 \\
\hline 4 & 2.5 & 100 & 24 & 0 & 0.7 & 0.7 & 1.25 & 700 & 16 & 1 & 0.1 & 1 & 1 \\
\hline 5 & 1.25 & 700 & 24 & 1 & 0.1 & 1 & 2.5 & 100 & 16 & 0 & 0.7 & 0.7 & 2 \\
\hline 6 & 1.25 & 700 & 24 & 1 & 0.4 & 0.4 & 2.5 & 100 & 16 & 0 & 0.1 & 1 & 2 \\
\hline 7 & 1.25 & 700 & 24 & 0 & 0.7 & 1 & 2.5 & 100 & 16 & 1 & 0.1 & 0.4 & 2 \\
\hline 8 & 2.5 & 700 & 24 & 1 & 0.7 & 1 & 1.25 & 100 & 16 & 0 & 0.1 & 0.4 & 1 \\
\hline 9 & 1.25 & 700 & 16 & 0 & 0.1 & 1 & 2.5 & 100 & 24 & 1 & 0.4 & 0.4 & 1 \\
\hline 10 & 1.25 & 700 & 16 & 0 & 0.7 & 0.7 & 2.5 & 100 & 24 & 1 & 0.1 & 1 & 1 \\
\hline 11 & 2.5 & 700 & 16 & 1 & 0.4 & 0.4 & 1.25 & 100 & 24 & 0 & 0.1 & 1 & 1 \\
\hline 12 & 1.25 & 700 & 16 & 1 & 0.1 & 1 & 2.5 & 100 & 24 & 0 & 0.7 & 0.7 & 1 \\
\hline 13 & 2.5 & 100 & 16 & 0 & 0.1 & 1 & 1.25 & 700 & 24 & 1 & 0.4 & 0.4 & 1 \\
\hline 14 & 1.25 & 700 & 24 & 0 & 0.1 & 1 & 2.5 & 100 & 16 & 1 & 0.4 & 0.4 & 1 \\
\hline 15 & 2.5 & 700 & 16 & 0 & 0.7 & 1 & 1.25 & 100 & 24 & 1 & 0.1 & 0.4 & 2 \\
\hline 16 & 2.5 & 100 & 24 & 0 & 0.1 & 1 & 1.25 & 700 & 16 & 1 & 0.4 & 0.4 & 2 \\
\hline 17 & 1.25 & 100 & 16 & 0 & 0.1 & 0.4 & 2.5 & 700 & 24 & 1 & 0.7 & 1 & 1 \\
\hline 18 & 2.5 & 700 & 24 & 0 & 0.7 & 1 & 1.25 & 100 & 16 & 1 & 0.1 & 0.4 & 2 \\
\hline 19 & 1.25 & 100 & 24 & 0 & 0.7 & 0.7 & 2.5 & 700 & 16 & 1 & 0.1 & 1 & 1 \\
\hline 20 & 1.25 & 100 & 16 & 0 & 0.4 & 0.4 & 2.5 & 700 & 24 & 1 & 0.1 & 1 & 2 \\
\hline 21 & 1.25 & 700 & 16 & 0 & 0.1 & 0.4 & 2.5 & 100 & 24 & 1 & 0.7 & 1 & 2 \\
\hline 22 & 2.5 & 100 & 16 & 0 & 0.1 & 0.4 & 1.25 & 700 & 24 & 1 & 0.7 & 1 & 2 \\
\hline 23 & 1.25 & 100 & 24 & 1 & 0.1 & 1 & 2.5 & 700 & 16 & 0 & 0.4 & 0.4 & 2 \\
\hline 24 & 1.25 & 700 & 24 & 0 & 0.4 & 0.4 & 2.5 & 100 & 16 & 1 & 0.1 & 1 & 2 \\
\hline
\end{tabular}

Table 5: Socio-demographic characteristics of respondents

\begin{tabular}{ll}
\hline Respondents & $397(83.8 \%$ of total $)$ \\
Mean age (standard deviation) & $45.64(14.9)$ \\
Age classes (class) & $1.3 \%[18-19), 37.0 \%[20-40), 48.4 \%$ \\
& {$[40-65), 13.4 \%[65-80)$} \\
Female respondents & $215(54.2 \%$ of completed) \\
Highest level of education & $7.3 \%$ Primary school, $50.9 \%$ High \\
& school , 34.5\% Higher education \\
& $6.8 \%$ Masters degree, $0.5 \%$ Doctors \\
& degree \\
& $17.9 \%[€ 5000-€ 15000), 23.9 \%$ \\
Income classes (class) & {$[€ 15000-€ 25000), 28.5 \%[€ 25000$} \\
& $-€ 35000), 15.9 \%[€ 35000-$ \\
& $€ 45000), 5.0 \%[€ 45000-€ 55000)$, \\
& $8.8 \%>€ 55000$ \\
\hline
\end{tabular}

arrive at their destination, while 53 respondents $(13.4 \%)$ that they start searching for parking before arriving at their destination.

The preferred parking type was off-street parking for 312 respondents $(78.6 \%)$. In case of a preference for off-street parking and not being able to find a vacant parking spot within 5 minutes, the majority of respondents (189 respondents, $60.6 \%$ ) stated they would go to the next nearest off-street parking facility while on-route searching for on-street parking, whereas 77 respondents $(24.7 \%)$ indicated they would go directly to the next nearest off-street parking facility. Only 46 respondents $(14.7 \%)$ responded that they 
Table 6: Socio-demographic characteristics of Dutch population (CBS, 2009)

\begin{tabular}{ll}
\hline Percentage of female & $50.5 \%$ \\
Age classes (class) & $35.5 \%[20-40), 49.0 \%[40-65), 15.4 \%$ \\
& {$[65-80)$} \\
Highest level of education & $5.4 \%$ Primary school, $55.1 \%$ High \\
& school , 32.2\% Higher education , \\
& $6.5 \%$ Masters degree, 0.6\% Doctors \\
& degree \\
\hline
\end{tabular}

would start searching for on-street parking. In case of a preference for on-street parking, the majority of respondents (60 respondents, $70.6 \%$ ) indicated that after 5 minutes searching without finding a vacant spot they would continue searching for an on-street parking spot, while 25 respondents $(29.4 \%)$ stated that they would in that case go to the nearest off-street parking facility.

The maximum searching or waiting time for a vacant parking spot (until moving to a different parking area) is 8.4 minutes (std. dev. 4.7 minutes) for drivers who prefer off-street parking and 12.9 minutes (std. dev. 8.4 minutes) for drivers who prefer on-street parking.

The responses from the choice situations in the third part of the survey are used to estimate a number of choice models presented in the next section.

\section{Discrete Choice Model Estimation}

In this section, a total of four choice models are estimated based on the stated preference experiments. We start with the multinomial logit model under the assumption of random utility maximization. To test the correlation in parking type the nested MNL model under RUM assumption is estimated with parking type as nests. To test heterogeneity in parking location choice preferences, the mixed MNL model under RUM assumption is estimated. And finally, to account for correlation between the 12 answers by each respondent a Panel Effect Mixed Logit is estimated. As mentioned earlier, choice models were estimated using the Biogeme software (Bierlaire, 2006) and they were validated using the mLogit Package in R (Croissant et al., 2012). The model results are presented in this section, after which the next section discusses what these results imply for parking location choice behaviour.

All model estimations are presented in Table 7 except for the Nested Logit model that did not yield results. Starting from the MNL model estimation, initially, alternative specific constants and socio-demographic characteristics were also included, however the effects hereof were not statistically significant. Hence, Table 7 shows the results of the final model. Here all coefficients have the expected sign, where price, walking distance and travel time are negative and parking type (where 1 indicates off-street parking) and parking availability upon arrival and after 8 minutes are positive.

The Nested Logit model structure was selected to be evaluated as it was suggested by Hunt \& Teply 1993) that parking decisions are correlated within parking type, and hence can be modelled using the Nested MNL model where on-street parking and off-street parking belong to different nests. The diagnostics of the estimated NMNL model showed that the nest structure on parking type does not give better model results, while at the same time it is indicated that the region of trust is too small. Therefor the NMNL model is rejected for further analyses.

For the RUM-MMNL model, the goodness of fit indicators and coefficient estimates are presented (Table 7). Heterogeneity in taste was tested for all coefficients, however only the model where the parking availability probability upon arrival was normally distributed yielded an increase in $\bar{\rho}^{2}$. Hence Table 7 shows the results of the final model, where this coefficient is normally distributed and all other coefficients are constant. All coefficients have the expected sign, and the RUM-MMNL model performs better than the RUM-MNL model according to the log-likelihood and $\bar{\rho}^{2}$.

The model with panel data is estimated with the Panel Effect to be used for all coefficients and found to be significant. Table 7 shows the goodness of fit indicators and coefficient estimates for the Panel Mixed 
Logit model. As can be observed from the log-likelihood and $\bar{\rho}^{2}$, the model gives a much better fit than the RUM-MNL model without panel data.

Table 7: Estimated Discrete Choice Models

\begin{tabular}{|c|c|c|c|c|c|c|c|c|c|}
\hline \multirow{2}{*}{$\begin{array}{l}\text { Coefficient/ } \\
\text { Constant }\end{array}$} & \multicolumn{3}{|c|}{ MNL } & \multicolumn{3}{|c|}{ Mixed Logit } & \multicolumn{3}{|c|}{ Panel Effect Mixed Logit } \\
\hline & Estimate & $\begin{array}{l}\text { Robust } \\
\text { Asympt. } \\
\text { std. } \\
\text { err. }\end{array}$ & t-stat & Estimate & $\begin{array}{l}\text { Robust } \\
\text { Asympt. } \\
\text { std. } \\
\text { err. }\end{array}$ & t-stat & Estimate & $\begin{array}{l}\text { Robust } \\
\text { Asympt. } \\
\text { std. } \\
\text { err. }\end{array}$ & t-stat \\
\hline$\beta_{C}$ & -0.735 & 0.032 & -22.85 & -0.91 & 0.093 & -9.83 & -1.824 & 0.118 & -15.43 \\
\hline$\sigma_{\beta_{C}}$ & - & - & - & - & - & - & 1.826 & 0.133 & 13.69 \\
\hline$\beta_{W}$ & -0.001 & $6 \mathrm{E}-05$ & -8.78 & -0.001 & 0 & -6.74 & -0.001 & 0.000 & -7.96 \\
\hline$\sigma_{\beta_{W}}$ & - & - & - & - & - & - & -0.002 & 0.000 & -10.16 \\
\hline$\beta_{T}$ & -0.011 & 0.005 & -2.44 & -0.014 & 0.006 & -2.52 & -0.025 & 0.009 & -2.63 \\
\hline$\sigma_{\beta_{T}}$ & - & - & - & - & - & - & 0.070 & 0.017 & 3.99 \\
\hline$\beta_{P}$ & 0.119 & 0.035 & 3.43 & 0.161 & 0.047 & 3.44 & 0.248 & 0.074 & 3.35 \\
\hline$\sigma_{\beta_{P}}$ & - & - & - & - & - & - & 1.676 & 0.137 & 12.26 \\
\hline$\beta_{P r^{0}}$ & 0.569 & 0.083 & 6.84 & 0.734 & 0.132 & 5.57 & 1.493 & 0.189 & 7.91 \\
\hline$\sigma_{\beta_{P r} 0}$ & - & - & - & 1.43 & 0.151 & 9.51 & -1.959 & 0.248 & -7.89 \\
\hline$\beta_{P r^{8}}$ & 1.180 & 0.071 & 16.54 & 2.38 & 0.721 & 3.31 & 2.767 & 0.198 & 13.98 \\
\hline$\sigma_{\beta_{P r} 8}$ & - & - & - & - & - & - & 3.267 & 0.249 & 13.14 \\
\hline \multirow{2}{*}{$\mathcal{L}(0)$} & \multicolumn{3}{|l|}{ - } & \multicolumn{3}{|l|}{-} & \multicolumn{3}{|l|}{-} \\
\hline & \multicolumn{3}{|l|}{3293.84} & \multicolumn{3}{|l|}{3293.84} & \multicolumn{3}{|l|}{3293.84} \\
\hline \multirow[t]{2}{*}{$\mathcal{L}(\hat{\beta})$} & \multicolumn{3}{|l|}{-} & \multicolumn{3}{|l|}{-} & \multicolumn{3}{|l|}{-} \\
\hline & \multicolumn{3}{|l|}{2912.33} & \multicolumn{3}{|l|}{2908.91} & \multicolumn{3}{|l|}{2305.70} \\
\hline $\bar{\rho}^{2}$ & \multicolumn{3}{|l|}{0.114} & \multicolumn{3}{|l|}{0.115} & \multicolumn{3}{|l|}{0.300} \\
\hline Iterations & \multicolumn{3}{|l|}{11} & \multicolumn{3}{|l|}{23} & \multicolumn{3}{|l|}{32} \\
\hline $\begin{array}{l}\text { Halton } \\
\text { draws }\end{array}$ & \multicolumn{3}{|l|}{-} & \multicolumn{3}{|l|}{3000} & \multicolumn{3}{|l|}{3000} \\
\hline
\end{tabular}

\section{Findings on Parking Choice Behaviour}

The survey results and model estimates reported in the previous sections yield a number of findings on parking location choice behaviour, in particular with regard to the (relative) importance of the tested factors. These findings are discussed here.

Firstly, recall that in the second part of the survey, where respondents were asked when they choose a parking location in case of an unfamiliar environment, the majority of respondents stated they start searching for parking once they approach $(13 \%)$ or arrive at $(50 \%)$ their destination, instead of deciding upon their parking location pre-trip. This in part explains the prevalence of traffic searching for parking, and the relevance of reducing cruising traffic by means of parking guidance and reservation systems. This first finding on strategic parking location choice behaviour highlights the importance of adequate parkingrouting policies, as well as the potential benefits of parking guidance and reservation systems for parking. It also supports the need to include such strategic pre-trip and on-route parking location choice decisions in urban traffic simulation models.

Secondly, from the various RUM logit-based models that were tested to describe drivers' parking decisions, the best fitting model is the mixed model where we account for the panel effects in the stated preference data. Compared to the other models, the mixed model for panel data differs with respect to heterogeneous preferences related to inter-drivers differences in the appreciation of all attributes examined.

Thirdly, the importance of the tested factors in determining drivers' parking decision is shown through the coefficient estimates. Note that the coefficient estimates cannot be directly compared between models 
(particularly with other models presented in literature) due to the fact that the coefficients are normalised for identification, while the normalisation depends on the model type as well as the utility specification. Hence the importance of the factors, as measured by the choice coefficients, should be interpreted relatively. One way of doing so is by considering the contribution of each factor to the total utility, as presented in Table 8 , where the contribution is computed as the product of its coefficient estimate and its mean attribute level. The factor that contributes most to the utility is the parking cost, followed by the probability of finding a vacant parking spot after 8 minutes. Apart from the parking availability factors, the ranking between the contribution of the other factors is roughly in line with what is found in other studies reported in literature (as for example presented by Van der Waerden (2012); Hunt (1988)) as well as with what was reported in the pilot studies. The only difference is found in the contribution of travel time to parking location and walking distance to destination. For these two attributes the walking distance was found to contribute more to the utility compared to what was found in other studies (e.g., Van der Waerden (2012); Polak et al. (1991)); something justified, given the larger walking distance and the shorter access times examined in these studies.

Table 8: Contributions in RUM-MMNL model for panel data

\begin{tabular}{lllll}
\hline Coefficient & Estimate & $\begin{array}{l}\text { Mean } \\
\text { attribute } \\
\text { level }\end{array}$ & $\begin{array}{l}\text { Absolute } \\
\text { contribution }\end{array}$ & $\begin{array}{l}\text { Relative } \\
\text { contribution }\end{array}$ \\
\hline$\beta_{C}$ & -0.821 & 1.875 & 1.539 & $44.7 \%$ \\
$\beta_{W}$ & -0.001 & 400 & 0.400 & $11.6 \%$ \\
$\beta_{T}$ & -0.013 & 20 & 0.260 & $7.6 \%$ \\
$\beta_{P}$ & 0.132 & 0.5 & 0.066 & $1.9 \%$ \\
$\beta_{P} r^{0}$ & 0.652 & 0.4 & 0.261 & $7.6 \%$ \\
$\beta_{P} r^{8}$ & 1.310 & 0.7 & 0.917 & $26.6 \%$ \\
\hline
\end{tabular}

The contributions of each factor in the other estimated models are presented in Table 9. The differences among the models are minor, while the rankings of the factors are the same across all models.

Table 9: Relative contributions in estimated models

\begin{tabular}{cccc}
\hline Coefficient & MNL & MMNL & Panel Effect MMNL \\
\hline$\beta_{C}$ & $44.30 \%$ & $45.40 \%$ & $44.7 \%$ \\
$\beta_{W}$ & $12.90 \%$ & $10.60 \%$ & $11.6 \%$ \\
$\beta_{T}$ & $7.10 \%$ & $7.40 \%$ & $7.6 \%$ \\
$\beta_{P}$ & $1.90 \%$ & $2.10 \%$ & $1.9 \%$ \\
$\beta_{P} r^{0}$ & $7.30 \%$ & $7.80 \%$ & $7.6 \%$ \\
$\beta_{P} r^{8}$ & $26.50 \%$ & $26.60 \%$ & $26.6 \%$ \\
\hline
\end{tabular}

Fourthly, we observe that the ratio between the coefficient estimate for the attribute pertaining to the probability to park after 8 minutes and that of the probability to park upon arrival is approximately 2 . This observation can be interpreted in two ways. Given that the parking probability after 8 minutes was tested on a higher range than the parking probability upon arrival, one interpretation is that the appreciation of uncertainty in parking availability is non-linear (regardless of the search time component). This would imply that the mean marginal benefit of an increase in parking probability within the range of 40-100\% is twice as high as the mean marginal benefit of an increase in parking probability within the range of 10-70\%. An alternative interpretation is that drivers accept spending time for searching or waiting for a parking spot to become available, and thus predominantly base their decision on the parking probability after this search time (where the marginal benefit of an increase in parking probability does not depend on the parking probability). This way, drivers' assign the same amount of utility to $x \%$ of probability for a vacant parking spot after 8 minutes as they do to $2 x \%$ of probability for a vacant parking spot upon arrival. These two interpretations are evidently not mutually exclusive. However, the latter interpretation is supported by respondents' responses in the second part of the survey where it was indicated that the 
maximum searching or waiting time they deemed acceptable (until moving to a different parking area) is on average 9.4 minutes. Furthermore, recall that it was found that this searching or waiting time appears related to the type of parking spot that is preferred, where drivers with preference for off-street parking indicate a lower maximum search time (mean 8.4 minutes, std. dev. 4.7 minutes) than drivers who prefer on-street parking (mean 12.9 minutes, std. dev. 8.4 minutes). The relevance of this finding for parking related policies is, that it indicates that individuals will typically visit a parking location and subsequently cruise for parking in cases when there is a high probability to find a vacant parking spot within an acceptable amount of time (which appears to be as high as 8-13 minutes), for example in cases with high turnover rate. This clearly yields cruising traffic. From a modelling perceptive, it indicates that assignment models may need to account for cruising for parking based on the probabilities of finding a vacant parking spot.

Fifthly, note that the responses towards uncertainty in parking availability and search times are evaluated between the range of 10 to $70 \%$ parking probability upon arrival and of 40 to $100 \%$ parking probability after 8 minutes. We believe this setup allows these results to be useful for preliminary testing of the potential benefits of parking guidance and reservation systems, where drivers would be given a parking location alternative with very high probability upon arrival (up to $100 \%$ ). Nevertheless, the facts that we found statistically significant differences in the way drivers appreciate the parking probability upon arrival, together with that our previous finding may suggest non-linearity in the appreciation of parking probabilities, underpins the relevance for further research into the behavioural responses towards such parking-oriented ITS.

\section{Concluding Remarks}

Being able to predict the decisions of drivers regarding their parking location is essential when developing parking-related policies, evaluating the potential of parking-related ITS and hence also in traffic assignment modelling. As the discussions in the earlier sections of this paper show, parking location choice behaviour affects the amount of traffic and distribution of traffic flows over the road network. Therefore the validity of assignment models (particularly within the context of parking-related simulation studies) relies on a valid model of drivers' parking location choice behaviour. Similarly, a valid understanding of drivers' parking location choice factors and their importance is needed when designing, evaluating and implementing parking policies and parking-oriented intelligent transport systems.

In this paper we present the results from a survey conducted among a representative panel of 397 respondents regarding parking location choice behaviour within the context of making a trip for shopping purposes and parking for a duration of 2-3 hours. The survey consisted of various questions on respondents' parking location choices and a stated preference experiment. The results were analysed by means of estimating a number of random utility maximisation choice models, where the mixed multinomial logit model accounting for panel data was found to fit best. The fact that the estimated parameters are in accordance with the body of literature on parking location choice suggests that the choice models and behavioural findings in this study can be generalised to other settings, although this has not been explicitly tested for and a meta-analysis would be required for a conclusive answer in this regard.

Main findings from the survey results and model estimates show:

- Searching for parking is prominent, where the majority of drivers will search for a parking spot as they approach or arrive at their destination, and are willing to spend up to 8-13 minutes on searching for a vacant spot.

- (Higher) availability of parking after 8 minutes of search time is more important than (lower) parking availability upon arrival.

- Uncertain parking availabilities rank second (for availability after 8 minutes) and fourth (for availability upon arrival) most important factors in determining parking location decision, where parking costs is ranked first, and walking distance to destination is ranked third.

- Drivers differ in their appreciation of finding a vacant parking spot upon arrival at their parking location. 
Furthermore, the fact that the best model fit was obtained when we accounted for panel effects in the stated preference data implies that heterogeneity in driver characteristics also play a role in parking location choices; however, this heterogeneity is uncorrelated with socio-demographic or socio-economic characteristics that were tested for.

A note can be made that in this study we described drivers' parking location choice under the assumption of utility maximisation. One may wish to investigate the suitability of this decision rule by considering alternative models based on, for example, prospect maximisation or regret minimisation.

The estimated choice models allow predicting drivers' parking decisions in terms of parking costs, walking distance to destination, travel time, parking type, and parking probabilities. Hence this model structure with these explanatory variables can be readily implemented in a traffic assignment model, where parking probabilities at a parking location can be computed based on the parking spot capacity, the arrival pattern of drivers and their (mean) parking duration. Note that the estimated parking location choice models do not include driver characteristics, and hence are suitable for both disaggregated microscopic simulation models as well as aggregated macroscopic assignment models.

In this study we analysed drivers' choice behaviour among alternative parking locations, in particular under uncertain parking availability and search times. As parking probabilities are shown to be important determining factors in drivers' parking decisions, this shows that parking guidance and reservation systems could be useful in reducing the amount of traffic searching for parking. This warrants further research into drivers' acceptance and willingness-to-pay towards such systems.

Anderson, S. P., \& de Palma, A. (2004). The economics of pricing parking. Journal of Urban Economics, 55, 1 - 20. URL: http://www.sciencedirect.com/science/article/pii/S0094119003000779. doi:10.1016/j.jue.2003.06.004.

Antony, J. (2003). 2 - fundamentals of design of experiments. In Design of Experiments for Engineers and Scientists (pp. 6 - 16). Oxford: Butterworth-Heinemann. URL: http://www.sciencedirect.com/science/article/pii/B978075064709050003X. doi:http://dx.doi.org/10.1016/B978-075064709-0/50003-X.

Arnott, R., \& Inci, E. (2006). An integrated model of downtown parking and traffic congestion. Journal of Urban Economics, 60, 418 - 442. URL: http://www.sciencedirect.com/science/article/pii/S0094119006000386. doi:10.1016/j.jue.2006. 04.004.

Axhausen, K., \& Polak, J. (1991). Choice of parking: Stated preference approach. Transportation, 18, 59-81. URL: http: //dx.doi.org/10.1007/BF00150559. doi:10.1007/BF00150559.

415 Axhausen, K., Polak, J., Boltze, M., \& Puzicha, J. (1994). Effectiveness of the parking guidance system in frankfurt/main. Traffic Engineering and Control, 35, 304-309.

Barata, E., Cruz, L., \& Ferreira, J.-P. (2011). Parking at the $\{$ UC $\}$ campus: Problems and solutions. Cities, 28, 406 - 413. URL: http://www.sciencedirect.com/science/article/pii/S0264275111000412. doi:http://dx.doi.org/10.1016/ j.cities.2011.04.001.

(2008). Parkagent: An agent-based model of parking in the city. Computers, Environment and Urban Systems, 32, 431 - 439. URL: http://www.sciencedirect.com/science/article/pii/S0198971508000689. doi:10.1016/j.compenvurbsys.2008.09.011. GeoComputation: Modeling with spatial agents.

Bierlaire, M. (2006). Biogeme: a free package for the estimation of discrete choice models. In Swiss Transport Research Conference TRANSP-OR-CONF-2006-048.

(2009). Efficient stated choice experiments for estimating nested logit models. Transportation Research Part B: Methodological, 43, 19 - 35. URL: http://www.sciencedirect.com/science/article/ pii/S0191261508000635. doi:http://dx.doi.org/10.1016/j.trb.2008.05.008.

Bonsall, P., \& Palmer, I. (2004). Modelling drivers car parking behaviour using data from a travel choice simulator. Transportation Research Part C: Emerging Technologies, 12, 321-347. URL: http://www.sciencedirect.com/science/article/pii/ S0968090X04000245. doi:10.1016/j.trc.2004.07.013.

Brandley, M., Kroes, E., \& Hinloopen, E. (1993). A joint model of mode/parking type choice with supply-constrained application. In 21st Annual Summer PTRC Meeting on European Transport, Highways and Planning (pp. 61-73).

Calthrop, E., \& Proost, S. (2006). Regulating on-street parking. Regional Science and Urban Economics, 36, 29 - 48. URL: http://www.sciencedirect.com/science/article/pii/S0166046205000475. doi:10.1016/j.regsciurbeco.2005.04.002. 
Caussade, S., de Dios Ortzar, J., Rizzi, L. I., \& Hensher, D. A. (2005). Assessing the influence of design dimensions on stated choice experiment estimates. Transportation Research Part B: Methodological, 39, 621 - 640. URL: http://www . sciencedirect.com/science/article/pii/S0191261504001055. doi:http://dx.doi.org/10.1016/j.trb.2004.07.006.

CBS (2009). Statistiek Netherlands. URL: http://www.cbs.nl.

ChoiceMetrics (2012). Ngene 1.1.1 User Manual \& Reference Guide.

440 Coppola, P. (2004). A joint model of mode/parking choice with elastic parking demand. In M. Patriksson, \& M. Labbe (Eds.), Transportation Planning (pp. 85-104). Springer US volume 64 of Applied Optimization. URL: http://dx.doi.org/10. 1007/0-306-48220-7_6. doi:10.1007/0-306-48220-7_6.

Croissant, Y. et al. (2012). Estimation of multinomial logit models in $\mathrm{r}$ : The mlogit packages. R package version 0.2-2. URL: http://cran. r-project. org/web/packages/mlogit/vignettes/mlogit. pdf, .

445 Dell'Orco, M., Ottomanelli, M., \& Sassanelli, D. (2003). Modelling uncertainty in parking choice behaviour. In 82nd Annual Meeting of the Transportation Research Board (pp. 1-20).

Gallo, M., D'Acierno, L., \& Montella, B. (2011). A multilayer model to simulate cruising for parking in urban areas. Transport Policy, 18, 735 - 744. URL: http://www.sciencedirect.com/science/article/pii/S0967070X11000217. doi:10.1016/j. tranpol.2011.01.009.

450 Gillen, D. (1978). Parking policy, parking location decisions and the distribution of congestion. Transportation, 7, 69-85. URL: http://dx.doi.org/10.1007/BF00148372. doi:10.1007/BF00148372.

Guo, L., Huang, S., Zhuang, J., \& Sadek, A. (2013). Modeling parking behavior under uncertainty: A static game theoretic versus a sequential neo-additive capacity modeling approach. Networks and Spatial Economics, 13, 327-350. URL: http: //dx.doi.org/10.1007/s11067-012-9183-1. doi:10.1007/s11067-012-9183-1.

Hensher, D. A. (2006). How do respondents process stated choice experiments? attribute consideration under varying information load. Journal of Applied Econometrics, 21, 861-878. URL: http://dx.doi.org/10.1002/jae.877. doi:10.1002/jae.877.

Hensher, D. A., \& King, J. (2001). Parking demand and responsiveness to supply, pricing and location in the sydney central business district. Transportation Research Part A: Policy and Practice, 35, 177 - 196. URL: http://www.sciencedirect. com/science/article/pii/S0965856499000543. doi:http://dx.doi.org/10.1016/S0965-8564(99)00054-3.

460 Hess, D. (2001). Effect of Free Parking on Commuter Mode Choice: Evidence from Travel Diary Data. Transportation Research Record: Journal of the Transportation Research Board, 1753, 35-42. URL: http://dx.doi.org/10.3141/1753-05. doi:10.3141/1753-05.

Hess, S., \& Polak, J. W. (2004). Mixed logit estimation of parking type choice. In Proc. of the 83rd Annual Meeting of the Transportation Research Board (Washington D.C., USA, January, 2004).

465 Hunt, J., \& Teply, S. (1993). A nested logit model of parking location choice. Transportation Research Part B: Methodological, 27, 253 - 265. URL: http://www.sciencedirect.com/science/article/pii/0191261593900359. doi:10.1016/ 0191-2615 (93) 90035-9.

Hunt, J. D. (1988). Parking location choice: insights and representations based on observed behaviour and the hierarchical logit modelling formulation. In Institute of Transportation Engineers (ITE), Annual Meeting, 58th, 1988, Vancouver, Canada.

470 Ibeas, A., dellOlio, L., Bordagaray, M., \& de D. Ortzar, J. (2014). Modelling parking choices considering user heterogeneity. Transportation Research Part A: Policy and Practice, 70, 41-49. URL: http://www.sciencedirect.com/science/article/ pii/S0965856414002341. doi:http://dx.doi.org/10.1016/j.tra.2014.10.001.

Kanafani, A. (1983). Transportation demand analysis. Number $\tau$. 1 in McGraw-Hill series in transportation. McGraw-Hill. URL: http://books.google.gr/books?id=KS5PAAAAMAAJ.

475 Kaplan, S., \& Bekhor, S. (2011). Exploring en-route parking type and parking-search route choice. In Proceedings of the 2nd International Choice Modelling Conference.

Kittelson \& Associates (2003). Transit Capacity and Quality of Service Manual volume 100. Transportation Research Board.

Krejcie, R. V., \& Morgan, D. W. (1970). Determining sample size for research activities. Educational and Psycholpgocal Measurement,

480 Lam, W. H., Li, Z.-C., Huang, H.-J., \& Wong, S. (2006). Modeling time-dependent travel choice problems in road networks with multiple user classes and multiple parking facilities. Transportation Research Part B: Methodological, $40,368-395$. URL: http://www.sciencedirect.com/science/article/pii/S0191261505000718. doi:10.1016/j.trb.2005.05.003.

Lambe, T. A. (1996). Driver choice of parking in the city. Socio-Economic Planning Sciences, 30, 207-219. URL: http://www. sciencedirect.com/science/article/pii/0038012196000080. doi:http://dx.doi.org/10.1016/0038-0121(96)00008-0.

485 Leurent, F., \& Boujnah, H. (2014). A user equilibrium, traffic assignment model of network route and parking lot choice, with search circuits and cruising flows. Transportation Research Part C: Emerging Technologies, 47, Part 1 , $28-46$. URL: http://www.sciencedirect.com/science/article/pii/S0968090X14002162. doi:http://dx.doi.org/10.1016/j.trc. 2014.07.014. Special Issue: Towards Efficient and Reliable Transportation Systems.

Levy, N., Render, M., \& Benenson, I. (2015). Spatially explicit modeling of parking search as a tool for urban parking facilities and policy assessment. Transport Policy, 39, 9-20. URL: http://www.sciencedirect.com/science/article/ pii/S0967070X15000165. doi:http://dx.doi.org/10.1016/j.tranpol.2015.01.004.

Liu, W., Yang, H., \& Yin, Y. (2014a). Expirable parking reservations for managing morning commute with parking space constraints. Transportation Research Part C: Emerging Technologies, 44, 185 - 201. URL: http://www.sciencedirect. com/science/article/pii/S0968090X14000916. doi:http://dx.doi.org/10.1016/j.trc.2014.04.002.

495 Liu, W., Yang, H., Yin, Y., \& Zhang, F. (2014b). A novel permit scheme for managing parking competition and bottleneck congestion. Transportation Research Part C: Emerging Technologies, 44, 265-281. URL: http://www.sciencedirect.com/ science/article/pii/S0968090X14001028. doi:http://dx.doi.org/10.1016/j.trc.2014.04.005.

Louviere, J. J., Hensher, D. A., \& Swait, J. D. (2000). Stated choice methods: analysis and applications. Cambridge University Press. 
McCoy, P., Ramanujam, M., Moussavi, M., \& Ballard, J. (1990). Safety comparison of types of parking on urban streets in nebraska. Transportation Research Board,

Mei, Z., Xiang, Y., Chen, J., \& Wang, W. (2010). Optimizing model of curb parking pricing based on parking choice behavior. Journal of Transportation Systems Engineering and Information Technology, 10, 99 - 104. URL: http://www. sciencedirect.com/science/article/pii/S1570667209600271. doi:10.1016/S1570-6672(09)60027-1.

Millard-Ball, A., Weinberger, R. R., \& Hampshire, R. C. (2014). Is the curb 80impacts of san franciscos parking pricing experiment. Transportation Research Part A: Policy and Practice, 63, 76 - 92. URL: http://www.sciencedirect.com/ science/article/pii/S0965856414000470. doi:http://dx.doi.org/10.1016/j.tra.2014.02.016.

Ottosson, D. B., Chen, C., Wang, T., \& Lin, H. (2013). The sensitivity of on-street parking demand in response to price changes: A case study in seattle, wa. Transport Policy, 25, 222 - 232. URL: http://www.sciencedirect.com/science/ article/pii/S0967070X12001886. doi:10.1016/j.tranpol.2012.11.013.

Polak, J., Axhausen, K., \& Errington, T. (1991). The application of clamp to the analysis of parking policy in birmingham city centre. In PTRC Summer Annual Meeting, 18th, 1990, University of Sussex, United Kingdom.

Rose, J. M., \& Bliemer, M. C. (2008). Stated preference experimental design strategies. Handbook of Transport Modelling, Elsevier, Oxford, (pp. 151-180).

Rose, J. M., Bliemer, M. C., Hensher, D. A., \& Collins, A. T. (2008). Designing efficient stated choice experiments in the presence of reference alternatives. Transportation Research Part B: Methodological, 42, 395-406.

Rose, J. M., \& Bliemer, M. C. J. (2009). Constructing efficient stated choice experimental designs. Transport Reviews, 29, 587-617. URL: http://dx.doi.org/10.1080/01441640902827623. doi:10.1080/01441640902827623. arXiv:http://dx.doi.org/10.1080/01441640902827623

Ruisong, Y., Meiping, Y., \& Xiaoguang, Y. (2009). Study on driver's parking location choice behavior considering drivers' information acquisition. In Intelligent Computation Technology and Automation, 2009. ICICTA'09. Second International Conference on (pp. 764-770). IEEE volume 3.

Shiftan, Y., \& Burd-Eden, R. (2001). Modeling Response to Parking Policy. Transportation Research Record: Journal of the Transportation Research Board, 1765, 27-34. URL: http://dx.doi.org/10.3141/1765-05. doi:10.3141/1765-05.

Shoup, D. C. (2006). Cruising for parking. Transport Policy, 13, $479-486$. URL: http://www.sciencedirect.com/science/ article/pii/S0967070X06000448. doi:10.1016/j.tranpol.2006.05.005. Parking.

Thompson, R. G., \& Bonsall, P. (1997). Drivers' response to parking guidance and information systems. Transport Reviews, 17, 89-104. URL: http://www.tandfonline.com/doi/abs/10.1080/01441649708716974. doi:10.1080/01441649708716974. arXiv:http://www.tandfonline.com/doi/pdf/10.1080/01441649708716974.

530 Thompson, R. G., \& Richardson, A. J. (1998). A parking search model. Transportation Research Part A: Policy and Practice, 32, 159 - 170. URL: http://www.sciencedirect.com/science/article/pii/S0965856497000050. doi:10.1016/ S0965-8564 (97) 00005-0

Van Der Goot, D. (1982). A model to describe the choice of parking places. Transportation Research Part A: General, 16, 109 - 115. URL: http://www.sciencedirect.com/science/article/pii/0191260782900036. doi:http://dx.doi.org/10.1016/ 0191-2607(82) 90003-6.

Van Ommeren, J. N., Wentink, D., \& Rietveld, P. (2012). Empirical evidence on cruising for parking. Transportation Research Part A: Policy and Practice, 46, 123 - 130. URL: http://www.sciencedirect.com/science/article/pii/ S0965856411001443. doi:10.1016/j.tra.2011.09.011.

Verhoef, E., Nijkamp, P., \& Rietveld, P. (1995). The economics of regulatory parking policies: The (im)possibilities of parking policies in traffic regulation. Transportation Research Part A: Policy and Practice, 29, 141 - 156. URL: http://www. sciencedirect.com/science/article/pii/0965856494E0014Z. doi:http://dx.doi.org/10.1016/0965-8564 (94)E0014-Z.

Van der Waerden, P. (2012). Pamela, a parking analysis model for predicting effects in local areas. PhD dissertation Technische Universiteit Eindhoven Department of Architecture, Building and Planning.

Van der Waerden, P., \& Oppwal, H. (1995). Modeling the combined choice of parking lot and shopping destination. In 7th World Conference on Transport Research July (pp. 16-21).

Young, W., \& Taylor, M. (1991). A parking model hierarchy. Transportation, 18, 37-58. URL: http://dx.doi.org/10.1007/ BF00150558. doi:10.1007/BF00150558. 